\title{
Discursos que instituem o tráfico de mulheres ${ }^{1}$
}

\author{
Anamaria Marcon Venson ${ }^{2}$
}

Joana Maria Pedro

A proposta deste artigo é dotar de historicidade o momento da emergência de certa configuração discursiva que tornou possível a visibilidade do tráfico de mulheres brasileiras para o comércio de sexo na Espanha. O objeto da investigação são formulações discursivas que constituíram o tráfico de pessoas como um problema na virada dos séculos XX e XXI. As fontes da pesquisa são notícias veiculadas na Folha de S. Paulo, jornal brasileiro de mais ampla circulação, e no El País, jornal espanhol de maior difusão. O recorte temporal é o espaço entre 1997 e 2007, período em que as referências ao tráfico ganharam regularidade no discurso midiático.

Palavras-chave: Tráfico Internacional de Mulheres - Discursividade - Mídia

\section{Coverage regarding trafficking in women}

The purpose of this article is to fix in history the moment when certain media coverage emerged which turned the spotlight on the trafficking of Brazilian women for the sex trade in Spain. The object of the investigation is media coverage which identified human trafficking as a problematic phenomenon around the turn of the twenty first century. The sources are news reports from two widely-read newspapers, Brazil's Folha de São Paulo, and Spain's El País. The time is the period between 1997 and 2007, when references to trafficking started to appear regularly in the media.

Keywords: international trafficking in women, discourses, media

\footnotetext{
${ }^{1}$ Artigo recebido e aprovado para publicação em janeiro de 2011.

${ }^{2}$ Doutoranda no Programa de Pós-Graduação Interdisciplinar em Ciências Humanas da UFSC, pesquisadora do LEGH - Laboratório de Estudos de Gênero e História. E-mail: anamariamarcon@ yahoo.com.br

${ }^{3}$ Doutora em História pela USP, professora da UFSC.E-mail: joanamaria.pedro@gmail.com
} 


\section{Discours instituant le trafic des femmes}

Le but de cet article est d'apporter une perspective historique au moment de l'émergence d'une certaine configuration discursive qui a rendu possible la visibilité du trafic de femmes brésiliennes pour un commerce sexuel en Espagne. Lobjet de cette enquête est composé de formulations discursives qui ont fait du trafic de personnes l'un des problèmes du passage du XXe au XXIe siècle. Les sources de cette étude sont des informations publiées par la Folha de São Paulo, un journal brésilien à grand tirage et dans El País, le journal espagnol le plus diffusé. La période étudiée se situe entre 1997 et 2007, une époque où les références au trafic sont devenues plus fréquentes dans le discours des médias. Mots-clés: trafic international de femmes, discursivité, média

"Meu livro é pura e simples ficção: é um romance, mas não fui eu que o inventei; foi a relação de nossa época e a sua configuração epistemológica com toda uma massa de enunciados." ${ }^{3}$ Dos princípios elaborados pelo afamado pensador francês Michel Foucault, este é um dos mais provocativos. Nesse artigo, tentamos operacionalizá-lo em perspectiva historiográfica para sinalizar o momento da emergência de certa configuração discursiva que tornou possível a dizi/visibilidade do tráfico de mulheres brasileiras para o comércio de sexo na Espanha, o momento em que o tráfico de pessoas se tornou uma questão. Nossas preocupações estão em torno das seguintes perguntas: sob qual luz o tráfico de pessoas pôde ser visto e sob quais enunciados pôde ser dito?

Submetemos à análise, em abordagem comparativa, textos publicados na Folha de S. Paulo, jornal produzido no Brasil, e no El País, jornal espanhol de maior difusão. Elegemos um jornal produzido na Espanha ao saber dos resultados da Pestraf (2003), Pesquisa sobre Tráfico de Mulheres, Crianças e Adolescentes, para fins de exploração sexual comercial, no Brasil, ${ }^{5}$ primeiro relatório que mapeou as principais rotas de tráfico no país. Esse extenso relatório apontou que a maior parte das brasileiras aliciadas para o comércio de sexo seriam mulheres e adultas, e que o principal destino internacional das rotas de tráfico seria a

\footnotetext{
${ }^{4}$ Michel Foucault, Sobre as maneiras de escrever a história. In: Michel Foucault, Ditos \& Escritos: arqueologia das ciências e história dos sistemas de pensamento, Rio de Janeiro, Forense Universitária, 2000 [1967], v. II, p. 69.

${ }^{5}$ Maria Lúcia Leal \& Maria de Fátima Leal (coord.), Pesquisa sobre tráfico de mulheres, crianças e adolescentes para fins de exploração sexual comercial no Brasil - Pestraf: Relatório Nacional - Brasil, Brasília, Cecria, 2003.
} 
Espanha. O objeto central dessa investigação são formulações discursivas sobre o tráfico internacional de mulheres que foram propagadas através da imprensa, que construíram imagens e produziram subjetividades, trazendo à cena questões que extrapolam fronteiras nacionais. Escolhemos como fontes para a pesquisa notícias publicadas entre os anos 1997 e 2007, período em que as referências ao tráfico de mulheres ganharam regularidade no discurso midiático.

Os jornais foram utilizados naquilo que continham sobre o mote deste trabalho, que é o tráfico internacional de mulheres. Demais detalhes de cunho jornalístico não foram aprofundados, já que poderiam constituir outra pesquisa, desviando-nos da questão central aqui apresentada. Foram contabilizadas 462 notícias relacionadas ao tráfico de mulheres e ao tráfico de pessoas, 130 no El País e 332 na Folha de S. Paulo (ver tabelas ao final). As fontes foram coletadas nos endereços eletrônicos que disponibilizam versões idênticas às versões impressas e algumas poucas exclusivamente digitalizadas: www.folhaonline.com.br e www. elpaís.com, nas seções "arquivo".

Para contar uma história de como a imprensa problematizou o tráfico internacional de mulheres para fins de exploração sexual na última década, preferimos utilizar o arsenal teórico foucaultiano, que sugere a desconstrução dos discursos que deram visibilidade e que tornaram dizível certa prática. Em tal metodologia aplicada à pesquisa histórica, discurso tem um sentido técnico particular. Não significa o que é dito. ${ }^{6}$ Discurso, aqui, é entendido como prática, pois é a prática que determina os objetos, e não o contrário; e só existe o que é determinado, afinal, as coisas não existem fora das práticas. ${ }^{7}$ Por esse ângulo, tráfico de mulheres, mercado sexual e prostituição são práticas datadas e dimensionadas por relações de poder. Estamos entendendo relações de poder como aparecem em Foucault: instáveis e possíveis de reversibilidade, disputas, embates, jogos estratégicos pelos quais indivíduos livres procuram se conduzir e determinar a conduta dos outros. ${ }^{8}$ Para esse autor, indivíduos não são somente objetos de disciplinas, mas também sujeitos, efeitos de modos de

\footnotetext{
${ }^{6}$ Paul Veyne, Como se escreve a História/Foucault revoluciona a história, Brasília, UnB, 1982.

${ }^{7}$ Michel Foucault, A ordem do discurso, São Paulo, Loyola, 1996.

${ }^{8}$ Idem, A vontade de saber, Rio de Janeiro, Graal, 1988; Idem, Sexo, poder e indivíduo, Desterro, Nefelibata, 2003.
} 
subjetivação. ${ }^{9}$ Estamos, portanto, tratando de discursos como uma prática que forma os objetos dos quais fala, e não como um conjunto de signos remetido a um conteúdo ou a uma representação. ${ }^{10}$ Desse modo, não é nossa intenção revelar uma interpretação ou descobrir um fundamento, mas estabelecer uma positividade, já que estamos, também, produzindo os objetos que recortamos. Nessa perspectiva, deveríamos lembrar que, assim como nossos textos acadêmicos são produzidos no interior de disputas, de relações de poder, de redes de saber e são estratégias, o discurso midiático também o é. Portanto, não se trata, aqui, de dar respostas conclusivas para a problemática que propusemos, mas justamente o contrário: tentamos mostrar que tráfico de mulheres se redefine constantemente a partir de diferentes discursos que lhe atribuem determinadas características, investem seus atores de atributos morais, explicam-no por meio de referências sociais e culturais, apontam causas e consequências. Nossa intenção é bagunçar o universo de imagens reconhecidas socialmente do tráfico de mulheres, mostrar mecanismos de poder presentes nas configurações discursivas, dissolver crenças em tal fenômeno, sem deixar de reconhecer exclusões e violências.

Tem-se insistido muito na complexidade do fenômeno do tráfico internacional de mulheres com fins de exploração sexual, tanto em debates sobre violações de direitos humanos quanto em lutas contra o crime organizado, em discussões sobre políticas de imigração e asilo, sobre desigualdades de gênero, pobreza e diferenças socioeconômicas dentro de cada país e entre países. Essas preocupações têm motivos reais e urgentes, mas são também constituídas em tramas discursivas e dimensionadas por relações de poder. No final do século XX, as facilidades de deslocamento de pessoas além das fronteiras nacionais trouxeram novas questões e sofisticaram os dispositivos de fiscalização, fazendo da imigração um foco de atenção, alvo de regulação rigorosa, fina e bem calculada. Constituiuse uma teia de observações, de discursos, de saberes, de análises, e o tráfico de pessoas, em particular o tráfico de mulheres para comércio sexual e o tráfico de

\footnotetext{
${ }_{9}^{9}$ Desenvolvido na série História da Sexualidade. A vontade de saber (publicado na França em 1976 e no Brasil em 1988), O uso dos prazeres (publicado na França e também no Brasil em 1984) e O cuidado de si (publicado na França em 1984 e no Brasil em 1985).

${ }^{10}$ Michel Foucault, Arqueologia do saber, Rio de Janeiro, Forense Universitária, 1986.
} 
crianças, tornou-se objeto de intolerância coletiva, de preocupação generalizada e de intervenções legislativas no campo do direito internacional.

Essa nova sensibilidade social com relação às mulheres vítimas de tráfico transnacional na virada dos séculos XX e XXI produziu sentidos e discursos que têm implicações práticas marcadas pelo gênero. $\mathrm{O}$ tráfico para comércio sexual, entendido como migração forçada, provoca grande alvoroço e pânicos morais, pois os debates sobre essa questão são, em geral, movidos por posições acerca da prostituição, fato que tem contribuído para que mulheres que se dedicam a essa atividade sejam alvo especial de investimentos e vigilâncias. Constituiu-se nos jornais um saber sobre o tráfico que concebe mulheres jovens em processos migratórios e inseridas no mercado sexual ora como vítimas, ora como infratoras. Infratoras não somente na ordem jurídica, mas também na ordem moral.

É possível estabelecer relações entre a intensa preocupação pela problemática do mercado do sexo transnacional nas viradas dos séculos XIX-XX e XX-XXI, dois momentos marcados pela inquietação em relação à migração. O mito das escravas brancas trazidas da Europa para as Américas no século XIX ecoa nos discursos atuais. Embora possamos traçar comparações entre histórias do passado e histórias que se desenrolam no presente, é preciso ficar claro que não se trata do mesmo fenômeno, como se a história se fizesse em ciclos, mas de acontecimentos distintos, pois são dimensionados por diferentes relações de poder. Os processos migratórios contemporâneos têm produzido novos sujeitos e diferentes modos de subjetivação, configurados por modelos de gênero, processos de racialização, grupo social, geração e nacionalidade.

Para fazer uma leitura historiográfica da constituição do tráfico de mulheres como foco de atenção na contemporaneidade, escolhemos, entre múltiplas práticas discursivas, textos midiáticos. Reconhecemos que há muitas outras perspectivas de análise, afinal, o objeto de que estamos tratando é produzido em embates discursivos. Portanto, a perspectiva desses dois jornais foi privilegiada em detrimento de outras não menos importantes para pensar a questão, fato que mostra que não estamos entendendo que esses textos desvelam um real, mas que estão fabricando verdades, produzindo um saber e são mecanismos repletos de intenções e estratégias.

Nos anos 1990, o tráfico já era noticiado nos jornais, mas aparecia em reportagens isoladas. Encontramos disponibilizadas no arquivo eletrônico do El País, jornal 
que entrou em circulação em 1976, somente oito notícias referenciando tráfico de mulheres desde a inauguração até a data que escolhemos para iniciar a análise. Em 4 de junho de 1988, feministas se manifestavam pela solidariedade entre Norte e Sul do planeta; em 25 de novembro de 1989, mulheres socialistas pediam boicote de "excursões sexuais" ao Terceiro Mundo; em 14 de julho de 1995, foi noticiada a prisão de 50 pessoas envolvidas em uma rede de tráfico de negras radicada na Nigéria; em 4 de dezembro de 1995, "Bruxelas denuncia a 'escravidão' do tráfico de mulheres do Leste Europeu”. Em 1996, um anúncio televisivo em 19 de abril; "Meio milhão de mulheres são vítimas de tráfico sexual na Europa" em 7 de junho; “Tráfico de mulheres e venda de esposas em domicílio através da internet" em 5 de julho; e "Menores nigerianas pedem asilo na Holanda e acabam em prostíbulos belgas" em 22 de setembro. $\mathrm{Na}$ Folha de S. Paulo, também aconteceu algo parecido com o que encontramos no $\mathrm{El}$ País. Tivemos acesso às notícias publicadas a partir de $1994^{11}$ e notamos que, em meados da década de 1990, o tráfico de mulheres figurava em referências ocasionais. Uma ou outra notícia tinha como mote o tráfico, e o que marca esse período são notícias sobre outros assuntos que citam o tráfico em algum ponto do texto. É fato que o alargamento da produção e a disseminação de informação marcaram o final do século XX. Contudo, assumimos o risco de afirmar que seria um engano ver nessa proliferação de discursos midiáticos sobre o tráfico no final da década de 1990, tanto no Brasil quanto na Espanha, um simples fenômeno quantitativo, um puro acréscimo acarretado simplesmente pela maior difusão e globalização dos meios de comunicação. Ao recompor o modo como o tráfico de mulheres ganhou discursividade na Folha de S. Paulo e no El País no final do século XX, insistimos na perspectiva de que se trata, senão da emergência de um problema, da reemergência de uma questão tramada em disputas internacionais e moldada por preocupações bastante particulares se comparadas àquelas de outros tempos.

Além do fato de os jornais passarem a noticiar o tráfico com regularidade somente no final da década de 1990, interessa também o fato de que o tráfico ganhou constância discursiva ao tempo em que foi associado ao crime organizado internacional. Em 18 de fevereiro de 2000, o El País publicou notícia a respeito de um estudo sobre máfias, diferenciando "delinquência de grande escala e de pequena escala". Ao tratar de delinquências de pequena escala, o texto articulou

\footnotetext{
${ }^{11}$ Embora tenhamos tido acesso a outras notícias, submetemos à análise somente aquelas publicadas entre 1997 e 2007.
} 
comércio de drogas, brigas de rua, furtos e roubos, prostituição de rua, ao passo que organizações terroristas, narcotráfico, máfias, tráfico de mulheres para prostituição e tráfico de imigrantes irregulares para trabalhar por salários de miséria são colocados no texto como crimes de grande escala. Falou-se que o combate à "delinquência de grande escala" é que precisaria de esforços conjugados, de cooperação internacional, de alto financiamento. A questão que se sobressai é um alarme contra o crime organizado, bem diferente daquelas notas isoladas sobre exploração de pessoas que caracterizaram os anos 1990.

O discurso do jornal brasileiro também foi se modificando de forma parecida. Em 15 de fevereiro de 1998, a Anti-slavery International, ONG britânica, falou de escravidão moderna associando migrantes escravizados por dívida ou por apreensão de documentos de identificação, exploração de crianças na indústria do turismo, casamentos forçados e tráfico de mulheres. O diretor dessa ONG, fundada em 1839 (informação dada pelo jornal), no contexto do regime colonial escravocrata, "acredita ter havido avanços na atuação do governo brasileiro no combate ao problema” e centrou o problema em âmbito nacional. Em 3 de dezembro de 1998, a notícia comemorativa "Direitos humanos 50 anos" colocou o tráfico de mulheres na lista das principais violências contra mulheres, ao lado de mutilação genital, remuneração desigual de trabalho feminino e masculino, violência doméstica, estupros, negação de participação na vida social. O mote da notícia era violência contra mulheres, que acontece no mundo inteiro, e não crime transnacional. Dizer que algo acontece no mundo todo é sutilmente diferente de dizer que algo acontece nas fronteiras, pois esta segunda situação cria mais justificativas para intervenções políticas entre os Estados. Nos anos 1990, entre uma nota policial e outra, a Folha de S. Paulo mencionou redes internacionais de prostituição e máfias, mas foi na virada do século que o discurso que articulava tráfico de mulheres para exploração sexual se transformou em modalidade de crime organizado transnacional.

Em 30 de junho de 1999, a Folha de S. Paulo publicou na íntegra a declaração de um acordo entre os governos da América Latina, Caribe e União Europeia, que objetivava "o fortalecimento de uma parceria estratégica". Assim dizia o item 26: "Congregar esforços para combater todas as formas de crime transnacional organizado e atividades afins, como lavagem de dinheiro, tráfico de mulheres, crianças e migrantes; a fabricação e o comércio ilícitos de armas de fogo, muni- 
ções e materiais conexos." E, em 26 de fevereiro de 2000, "EUA criticam saláriomínimo brasileiro" tratou de um relatório que elencava como problemas graves no país "a discriminação em relação aos afro-brasileiros e a violência contra os homossexuais, além de trabalho forçado, da prostituição infantil e do tráfico de mulheres e crianças." Na virada do século, os enunciados sobre tráfico foram se intensificando, se reforçando, tanto em números de notícias quanto em força argumentativa. No dia 16 de julho de 2000, o tráfico estampou a primeira página da Folha de S. Paulo: "Escravidão moderna", dizia o anúncio, que vinha acompanhado de foto com a legenda "João Felipe e sua mulher, Maria, com foto da filha Simone, morta na Espanha; o tráfico de mulheres no mundo gera até US\$ 12 bi por ano". Nesse dia, foram publicadas sete reportagens sobre tráfico na Folha de S. Paulo: "Goiana morreu após três meses na Espanha", "Tráfico de mulheres gera até 12 bi/ano", "Gigolôs ganham milhões nos Estados Unidos", "EUA realizam campanha para combater a prática", "Comércio de gente", "Asiáticas são as principais vítimas do tráfico", "Península Ibérica é destino de brasileiras". Falou-se aí do famoso "caso Simone", que ganhou especial atenção na Pestraf. ${ }^{12}$ Poderíamos ter escolhido discutir se foi o caso Simone que desencadeou essa proliferação de notícias nesse dia ou se foi a intensa atenção dada ao tráfico nessa época que fez o caso Simone estampar a primeira página, mas nos preocupamos em analisar como esses discursos entraram em circulação, com quais questões se relacionavam, quem estava falando sobre tráfico, que saber se formulou a partir daí. Vejamos como começa a reportagem “Tráfico de mulheres gera até US\$ 12 bi/ano”:

Crime é a terceira fonte de renda do crime organizado e já preocupa países desenvolvidos. O tráfico de mulheres e crianças faz anualmente até um milhão de vítimas em todo mundo e já é a terceira maior fonte de renda para o crime organizado internacional, atrás somente do comércio ilegal de drogas e de armamentos.

Nessa data, o tráfico já aparecia rodeado de números que o comprovavam. Não se tratava simplesmente de denúncias de exploração, ao modo que se fez nos anos 1990, mas de dados, de relações de causalidade, de métodos de combate, de intenção de definir sujeitos, de mapear lugares e rotas, de cálculos bem apurados. Estavam aí divulgados relatórios do FBI (polícia federal americana) e da Agên-

${ }^{12}$ A brasileira Simone, natural de Goiânia, morreu aos 25 anos na Espanha em 1996. A Polícia Federal foi requisitada para tratar de um caso de tráfico e a família de Simone levou o caso à Justiça brasileira. 
cia de Inteligência dos Estados Unidos (CIA). Estavam aí anunciados preços de serviços prestados pelas mulheres envolvidas, lucros dos grupos de traficantes, quanto o cliente pagava, quanto ficava com o bordel, os custos de um passaporte falso, as comissões dos aliciadores, o tempo médio das relações sexuais prestadas, cifras das dívidas adquiridas pelas mulheres. Tivemos também notícia de várias ONGs que se dedicavam à questão, além das famosas instituições internacionais. Estavam mapeadas rotas, cidades em que a prática ocorria com regularidade; grupos criminosos envolvidos tinham nome e nacionalidade conhecida. É intrigante o fato de essas instituições terem tão pretensiosa medida de números e informações que diziam o tráfico e, ao mesmo tempo, alardearem que o tráfico estaria aumentando e que estaria fora de controle. A reportagem "EUA realizam campanha para combater a prática”, ainda nessa série de 16 de julho de 2000, é uma entrevista com a diretora do conselho responsável pelo lançamento da campanha Stop Trafficking em 1998, promovida pelos Estados Unidos. Ela dizia que "a principal causa do tráfico é o desespero econômico [...] o tráfico é uma atividade que cresce porque é muito lucrativa”. Mas a diretora não foi clara sobre quem se beneficiaria dessa lucratividade. E disse ainda:

a questão do tráfico de mulheres é uma questão internacional [...] A política do Departamento de Estado [dos Estados Unidos] está voltada para o desenvolvimento da democracia, da prosperidade econômica e da segurança mundial. E o tráfico interfere em todas essas questões [...] Fazemos alertas em outros países para que as pessoas saibam que, quando estão indo trabalhar em outros países em empregos que prometem ser lucrativos, na verdade, podem cair nessa rede de tráfico e se verem envolvidas em uma situação de escravidão. Nós também gastamos dinheiro para ajudar a reintegração das vítimas até elas retornarem aos seus países. E também estamos lutando para o desenvolvimento de leis mais rígidas para combater esse tipo de crime.

Estava aí bem enfatizada uma preocupação com o controle de fronteiras, e não somente um controle da mobilidade de pessoas, mas também um controle de movimentações financeiras. Estamos entendendo que, na perspectiva desse discurso, a democracia está garantida porque está a serviço da prosperidade econômica e da segurança mundial. Falou-se de reintegração de vítimas ao mesmo tempo em que se falou do seu retorno aos países de origem. O tráfico foi colocado em discurso como "questão internacional", como questão de pessoas que "estão indo trabalhar em outros países em empregos que prometem ser lucrativos". 
Não há o que ler nas entrelinhas, está tudo aí. Por certo que havia preocupação humanitária, bastante justa, mas parece que a batalha antitráfico agregou também outros objetivos. Poderíamos dizer que a legislação que se ocupa desses processos responde a certos interesses, normalmente aos interesses dos Estados que recebem imigrantes, além de interesses humanitários. A intensa atenção dada à imigração que marca nosso tempo foi a condição histórica desse novo campo de visibilidade em que se constituíram definições do tráfico de pessoas. Imigração irregular e tráfico de pessoas são discursos que historicamente vieram de par, e isso tem se evidenciado recentemente também no discurso midiático. Essa constatação não é de fato muito nova, ${ }^{13}$ mas o que tentamos investigar foi como essa discursividade se propagou através da imprensa e desamarrar algumas teias da constituição do tráfico como um problema.

É precisamente na virada do século que o problema do tráfico desdobrou-se e passou a ser percebido no interior de um jogo de relações internacionais, configurado por crises econômicas que extrapolavam fronteiras políticas. Essas tensas relações foram trazidas à cena nas páginas dos jornais. Em 14 de dezembro de 1999, El País publicou, sem explicação da fonte, que "95\% das mulheres que exercem prostituição são imigrantes exploradas por redes ilegais". Em 24 de junho de 2000 , outra estatística, também sem fonte, colocou que " $70 \%$ das mulheres que exercem prostituição em Madri são imigrantes" e que a maior parte delas viria da América Latina. Em 22 de julho de 2000, o jornal publicou que " $80 \%$ das mulheres que exercem prostituição em Madri são imigrantes da África Subsaariana, América Latina e Leste Europeu". Em 11 de dezembro de 2000, desta vez com fonte indicada, o jornal apresentou um informe da ONG Médicos do Mundo, baseado em atendimentos médicos, segundo o qual 63,2\% das profissionais do sexo na Espanha seriam estrangeiras, 69\% da África Subsaariana, 20,5\% latinoamericanas e 8,2\% europeias. Em 24 de setembro de 2002, sem fonte explícita,

\footnotetext{
${ }^{13}$ Sobre associações entre migração e tráfico: Bridget Anderson, Motherhood, apple pie and slavery. Reflections on trafficking debates, Oxford, Centre on Migration, Policy and Society, 2007; Laura Augustín, "La industria del sexo, los migrantes y la família europea", Cadernos Pagu, Campinas, v. 25, jul./dez. 2005; Kamala Kempadoo \& Jo Doezema (org.), Global sex workers. Rights, resistence and redefinition, Nova York/Londres, Routledge, 1998; Davida, "Prostitutas, 'traficadas' e pânicos morais: uma análise da produção de fatos em pesquisas sobre o 'tráfico de seres humanos", Cadernos Pagu, Campinas, n. 25, jul./dez. 2005; Caroline Aussuerer, Controle em nome da proteção. Análise crítica dos discursos sobre o tráfico internacional de pessoas, 2007, 170 f., Dissertação de Mestrado em Relações Internacionais - Pontifícia Universidade Católica do Rio de Janeiro.
} 
El País publicou que "mais de 21 mil mulheres exercem a prostituição nos 1.404 clubes na comunidade de Málaga" e que 70\% delas seriam estrangeiras. Em abril de 2007, o jornal noticiou que uma rede russa "colocou umas 2.000 jovens prostitutas russas na Espanha nos últimos 3 anos". Em 3 de julho de 2007, dados da Polícia e Guarda Civil: "umas seis mil mulheres russas foram exploradas por rede em Almería”. Em 16 de dezembro de 2007, sem apresentar a fonte da informação, o jornal apontou que " $85 \%$ das prostitutas que exercem sua 'profissão' na Espanha o fazem forçadas pelas máfias" e que mais de meio milhão de mulheres e meninas seriam vítimas desse fenômeno.

Um amontoado de cifras, números, estatísticas, que algumas vezes se contradizem, somados a uma multiplicação de discursos que tomaram o tráfico de mulheres como objeto, fizeram dessa prática um motivo de alarme e anexaram-na à questão migratória. El País centralizou a questão no fato de essas mulheres serem estrangeiras, e não no problema da exploração. Em 24 de junho de 2000, anunciou que " $70 \%$ das mulheres que exercem prostituição em Madri são imigrantes". O texto que acompanhava dizia que a prostituição estaria relacionada "à pobreza, à desigualdade, à dependência de drogas, à migração, aos abusos sexuais na infância e aos maus tratos", e que é um "fenômeno que passou do localismo à internacionalização, pois se criaram redes mundiais de tráfico de mulheres e um mercado de grandes benefícios para os exploradores", traçando uma rede de causalidade para o problema. Um olhar mais atento poderia, talvez, inverter a direção dessa análise. Poderíamos aventar que a pobreza, a desigualdade, a imigração é que teriam sido motivadas pelas redes mundiais de comércio, pelo mercado internacionalizado, globalizado. A análise das fontes aponta a forma como os discursos sobre tráfico compuseram discursos sobre imigração e como essas narrativas referem-se mutuamente, reforçam-se reciprocamente nos jornais.

Muitos números foram arrolados para mostrar o dinheiro em jogo no negócio das redes migratórias e exploração sexual. Em 17 de dezembro de 2002, em notícia do El País cujo mote era o tráfico de mulheres, lemos que a União Europeia "gastará 934 milhões nos países de origem para frear a imigração". Em 26 de janeiro de 2003, o Instituto da Mulher informava que a venda de sexo movia na Espanha mais de 72 milhões de euros. Em outubro de 2003, um informe da Comissão para a Investigação de Maus Tratos a Mulheres afirmava que clubes de prostituição são um negócio que rende 12 milhões na Espanha anualmente. Em 
2 de março de 2007, a ONU informava que o tráfico sexual movia mais milhões que a venda de armas ou drogas. Dias depois, em 15 de março, lemos novamente que o tráfico de mulheres era o segundo negócio ilícito mais lucrativo do mundo, acima da venda de armas e drogas, repetição que mostra a importância dada à questão. Em 20 de abril de 2007, El País publicou que uma agência que aliciava mulheres russas enviava 650 mil euros anualmente para Rússia e estava sendo investigada por envio ilegal de dinheiro para o exterior. Em 3 de julho de 2007, lemos um informe policial explicando que, durante os últimos três anos, um milhão de euros teriam sido enviados para a Rússia. Embora houvesse uma intenção de precisão, não encontramos nenhuma explicação explícita de como esses dados foram obtidos, mas poderíamos arriscar que eram derivados de investigações policiais sobre movimentação financeira irregular, e não sobre exploração de pessoas. Seguindo as condições de surgimento e de funcionamento dos discursos sobre o tráfico de mulheres para exploração sexual, procurando a maneira como se formaram, podemos notar discursos cuidadosamente inscritos em exigências de controle de fronteiras. É notável nessa repetição de números que se referem à movimentação financeira uma preocupação de ordem econômica, muito mais enfatizada que preocupações de ordem humanitária.

Enquanto no El País o tráfico foi se delineando como um problema em torno da discussão sobre crime organizado internacional, na Folha de S. Paulo a questão entrou em discurso associada a pressões internacionais contra a exploração sexual. Em 31 de maio de 2001, a Folha de S. Paulo informou que a OIT (Organização Internacional do Trabalho) investiria grande quantia de dinheiro em um projeto de rastreamento de rotas domésticas e internacionais de tráfico de mulheres, adolescentes e crianças na região Norte do país. Tal projeto fazia parte de um estudo nacional coordenado pelo Cecria (Centro de Referência, Estudos e Ações sobre Crianças e Adolescentes), ONG de Brasília. Poderíamos investigar se organizações brasileiras estavam utilizando a temática para arrecadar financiamento para pesquisas, ou se instituições internacionais estavam utilizando organizações brasileiras para controlar os fluxos de pessoas, mas o que importa, aqui, é pensar os efeitos de tal colaboração, os discursos que se colocaram em funcionamento e que sustentaram a preocupação com o tráfico, e quais sujeitos estavam envolvidos. A coordenadora do Cecria disse que "espera contar com a colaboração de organizações não governamentais, entidades ligadas às igrejas, secretarias 
de segurança, Interpol, entre outras organizações". Enquanto no El País sobressaiu-se a preocupação com o controle de ondas migratórias, por aqui se falou de cooperação internacional para "levantar informações para ajudar as autoridades policiais a combater esse crime, que está ligado, na maioria os casos, à exploração sexual". Em 13 de julho de 2001, a Folha de S. Paulo citou a coordenadora de projetos de cooperação técnica internacional entre o Fundo de Desenvolvimento das Nações Unidas para a Mulher e o Departamento da Criança e do Adolescente do Ministério da Justiça: “o Brasil assinou um protocolo contra o tráfico de seres humanos, e pretendemos trabalhar mais eficazmente com outros países para prevenir e combater essa prática". É bem nessa data marcada por fervores antiimigração que várias instituições foram mobilizadas para solucionar o tráfico de pessoas, entendido como um problema de fronteiras transnacionais. Se, por um lado, os Estados que estavam recebendo migrantes planejaram e pressionaram intervenções nos países que supostamente dariam causa a essa "forma moderna de escravidão", é certo que esses países também jogaram com as pressões externas para arrecadar ajudas financeiras. Ainda na reportagem do dia 13 de julho de 2001, cujo subtítulo era "EUA querem impor sanções econômicas em 2003 contra países que não tomem medidas efetivas contra a prática”, lemos um trecho de um relatório divulgado pelo Departamento de Estado norte-americano:

o governo do Brasil ainda não atende totalmente a padrões mínimos recomendados pelos EUA, como investigações, proteção às vítimas, extradição de criminosos e medidas legais para punir funcionários do governo que tenham defendido medidas brandas demais contra traficantes de seres humanos ou "desculpando" os criminosos.

Por certo que havia preocupações humanitárias nesse discurso. Mas estamos falando, também, de como o tráfico de pessoas serviu de justificativa para intervenções políticas e econômicas entre os Estados, de como esses discursos fizeram funcionar a lógica do mundo globalizado e suas exclusões. O que estamos tentando mostrar é a maneira como o tráfico se constituiu como efeito e suporte de relações de poder, a maneira como se formulou um saber sobre o tráfico e como esse saber foi disseminado pelo discurso midiático. Ainda citando tal relatório, a Folha de S. Paulo anotou que "o governo brasileiro investiga casos de tráfico ativamente. Entre 1996 e 2000, tribunais condenaram 94 pessoas ou grupos por tráfico". A medida são as condenações! Bem, a questão, aqui, não é procurar pistas daquilo que acontece na realidade, pois estamos tratando esses discursos jor- 
nalísticos como realidade, afinal eles produzem efeitos, têm materialidade, criam sujeitos. Por isso mesmo, é certo que esses discursos que deram visibilidade ao tráfico não estavam desassociados do momento do qual eram, ao mesmo tempo, efeito e motivação, havendo intrínseca conexão entre tais textos e os contextos históricos em que foram produzidos.

O tráfico ganhou visibilidade no El País principalmente nas sessões Sociedad, Tribuna (lugar de comentaristas contratados e leitores participantes), España e, em menor medida, na sessão de assuntos internacionais. Na Folha de S. Paulo, falou-se de tráfico principalmente nas sessões Cotidiano e Mundo; com frequência considerável na sessão Ilustrada publicizando filmes e espetáculos; mas também em sessões aparentemente sem relação com a questão, como, por exemplo, na Esporte, para falar da Copa do Mundo; na Dinheiro, para falar de transferências financeiras transnacionais; na Informática, para falar de turismo sexual e aliciamento pela Internet. Poucas menções apareceram nas sessões Brasil e Opinião, e pelo menos duas ganharam a primeira página. Foram submetidas à análise 174 notícias publicadas na Folha de S. Paulo cujo mote era o tráfico de mulheres. Destas, 78, mais da metade, tratavam principalmente, quando não exclusivamente, de operações policiais relacionadas ao tráfico. Esse dado, somado à análise da totalidade das publicações sobre tráfico na Folha de S. Paulo, aponta que o assunto foi problematizado nesse jornal, de modo geral, como uma questão de polícia. A quantidade de notícias publicizando o trabalho policial de tentar desfazer as redes de tráfico no Brasil vai aumentando, de maneira quase proporcional, à medida que outras notícias sobre acordos internacionais e pesquisas sobre o tráfico aumentam. Isso poderia ser entendido como uma resposta das polícias às cobranças tanto do governo brasileiro quanto da sociedade por um combate à exploração de mulheres. Após a Convenção de Palermo, em 2000,,$^{14}$ aparecem noticiados vários outros acordos e relatórios internacionais sobre o tráfico de pessoas mostrando a constituição do tráfico como um problema. A Pestraf, primeiro relatório de âmbito nacional dedicado a mapear as rotas do tráfico no Brasil, desempenhou importante papel nessa disputa de saberes. É justamente na data de sua publicação em Brasília, julho de 2003, que o trabalho policial passa

\footnotetext{
${ }^{14}$ Convenção assinada em Assembleia Geral da ONU que deliberou normativa supranacional contendo uma definição para o tráfico de pessoas, bem como medidas e técnicas especiais de investigação na prevenção, controle e combate ao crime organizado. Vigora internacionalmente desde 2003, ratificada pelo Brasil em 2004 e pela Espanha em 2002.
} 
a ser noticiado nas páginas do jornal com bastante regularidade e enfatizando operações de desmantelamento de rotas do tráfico. Constituiu-se, nas páginas do jornal, um arquivo de procedimentos policiais que se perdem em meio a relatórios de cobrança internacional e em meio a declarações de pena e desprezo pela prostituição, tornando impossível definir os responsáveis pela colocação do tráfico em discurso. Um discurso é condição de existência do outro, e assim vão se propagando. Em 4 de dezembro de 2004, a palavra do delegado é requisitada: "A prisão do grupo representa o desfecho da organização criminosa, consagrando nosso compromisso de reprimir o ilícito tráfico de mulheres." Se o controle policial se fez, foi por uma série de reivindicações por parte dos Estados, de organizações, de encarregados de garantir os direitos humanos, e até de "vítimas" pedindo algum benefício. Por sua vez, esses relatórios e organizações diversas se apoiam, muitas vezes, em dados policiais, tecendo uma complexa rede de saberes.

Se o tráfico internacional de mulheres foi tratado como uma questão de polícia, os discursos foram organizados também em função de uma discussão sobre crime organizado, tanto na Folha de S. Paulo quanto no El País. Em 7 de agosto de 2003, a Folha de S. Paulo anunciava, já no título de uma notícia, uma descrição de atividades relacionadas ao crime organizado: "acusados de falsificação de passaportes, contrabando e lavagem de dinheiro", acompanhada de texto que narrava a investigação de um possível envolvimento do grupo com tráfico de mulheres e crianças para o exterior. Em fevereiro de 2004, ainda nesse jornal brasileiro, uma relação semelhante: preso "um mafioso acusado de crimes de lavagem de dinheiro, tráfico de drogas, tráfico de mulheres e homicídio"; e, em 2 de abril de 2006, "governos não têm como combater pirataria e tráfico, negócios em expansão". Em 12 de dezembro do mesmo ano, a Folha de S. Paulo mencionava máfia italiana que traficaria mulheres, grupo que estaria envolvido em crimes de lavagem de dinheiro, tráfico interno e internacional de pessoas, formação de quadrilha, manutenção de casa de prostituição e crime contra o sistema financeiro, isso tudo na mesma notícia. Ainda em dezembro de 2006, lemos sobre a prisão de italianos por tráfico de mulheres e por lavagem de dinheiro. Em 20 de janeiro de 2007, o mesmo jornal publicou uma notícia sobre a extradição de 15 pessoas procuradas pela Justiça americana, líderes de organizações criminosas do tráfico de drogas, acusados de narcotráfico, assassinato, tráfico de mulheres para exploração sexual e abusos contra menores. Em 16 de fevereiro de 2007: "Espanha 
prende casal suspeito de traficar brasileiras", e terminou a notícia dizendo que "a polícia espanhola deteve ainda um homem e duas mulheres, também brasileiros, que estavam em situação irregular no país". Apesar do título, o texto não falava de tráfico de pessoas, o que exige uma reflexão sobre o fato de o tráfico de mulheres estar sendo usado como recurso de sedução midiática. Em 12 de agosto de 2007, noticiou a prisão da chamada baronesa do sexo, "apontada como uma das maiores cafetinas do país [...] acusada de extorsão, favorecimento da prostituição, manutenção de casa de prostituição e tráfico de mulheres".

Essa extensa citação de crimes relacionados ao tráfico de pessoas na Folha de S. Paulo mostra que, assim como El País deu sentido ao tráfico associando-o a redes de imigração ilegal que trazem consigo falsificação documental e movimentação financeira irregular, o discurso midiático brasileiro também se articulou veiculando estreita relação entre tráfico de pessoas e de drogas, lavagem de dinheiro e prostituição. É certo que há relações entre essas atividades, mas o que é interessante notar é que, em meados da década de 1990, o tráfico de mulheres aparecia no jornal brasileiro de maneira isolada, pouco noticiado e desassociado de outras atividades, e isso foi mudando no decorrer do período, produzindo implicações práticas na maneira como percebemos o "fenômeno". Bem no final do século XX, o tráfico começou a ser percebido no interior de uma rede de crimes relacionados, mostrando como se produziram sentidos sobre ele e a maneira como esses sentidos foram disseminados através da imprensa.

"Brasil lidera exportação de escrava sexual" é título de notícia publicada na Folha de S. Paulo no dia 29 de novembro de 2000. O discurso sobre exploração de pessoas tanto se mistura ao discurso sobre comércio ilegal que até os termos utilizados se confundem. Essa reportagem informava, entre outras pesquisas, sobre um levantamento realizado pelo Itamaraty que apontava que o principal destino das brasileiras que saíam do país para se inserir no mercado sexual seria a Espanha. Somos informados, também nesse dia 29 de novembro de 2000, que, em 1998, 461 brasileiros foram deportados da Espanha por estarem com documentação em situação irregular. O diplomata brasileiro que cuidava do problema no Ministério das Relações Exteriores explicou que, "desses, a esmagadora maioria era[m] mulheres que voltavam após uma experiência frustrada de prostituição”. Que tráfico e imigração sejam associados no discurso não é de fato uma asserção muito nova, mas o que estamos tentando mostrar aqui é como o tráfico ganhou 
discursividade articulado à ideia de prostituição como estratégia migratória, como essa discursividade foi propagada através da imprensa e como o tráfico é articulado segundo múltiplos pontos. Dessa vez, a palavra do diplomata foi requisitada e atribuiu sentido ao tráfico.

Em 11 de dezembro de 2000, foi a vez do sociólogo Íñigo Asensio falar ao El País. "Que relação tem uma prostituta estrangeira que trabalha na Casa de Campo [conhecido ponto turístico e local de prostituição noturna] de Madri com o Produto Nacional Bruto da Nigéria?” E o sociólogo, armado de seu saber e poder, explicou: "O envio de fundos aos países de origem contribui para manter contatos entre imigrantes e suas comunidades de origem. Constitui um fator de segurança para regressar à sua pátria, quando finalizar o episódio da emigração." E o jornal completou: as associações de migrantes na Nigéria se chamam "Cooperativas para o Melhoramento do País. Através delas, viajantes enviam remessas de dinheiro individuais e coletivas. Estas quantidades constituem uma fonte importante de entrada de dinheiro para seus respectivos países". O essencial, aqui, é notar uma multiplicação de discursos que evocam o tráfico como um problema, os múltiplos focos dos quais tais discursos são emitidos, e que vão construindo, de fragmento em fragmento, um saber sobre o tráfico. Não se trata simplesmente do discurso de um Estado contra o outro, mas de uma multiplicação discursiva irradiada de múltiplos pontos, que vão se entrelaçando e formulando um saber.

Ao noticiar a Convenção de Palermo, em 13 de dezembro de 2000, El País metaforizou:

Palermo, onde nasceu e cresceu este gigantesco monstro de mil tentáculos [a máfia], pretende agora levantar a bandeira de luta contra as máfias transnacionais que administram o tráfico de seres humanos, a prostituição, a pornografia na Internet, o comércio de órgãos humanos e o tráfico de drogas em todo o mundo. Máfias globais contra as quais até agora não havia existido uma estratégia internacional de luta.

E, em 16 de dezembro de 2000, o jornal espanhol informou que alguns países negaram-se a assinar o Protocolo: "Marrocos, por exemplo, não se sente especialmente urgido a gastar milhões em algo que não trará necessariamente benefícios ao país." Se os discursos são estratégias, e se sabe que estamos falando de um jogo de interesses conflitantes, de relações de poder, é possível pensar práticas de poder que fizeram funcionar o discurso de que o tráfico de mulheres é um problema prioritário na contemporaneidade, pois se constituiu em uma rede de alianças inter- 
nacionais para combater essa prática a ponto de articular tratados e de justificar sanções políticas e econômicas entre os países em nome da batalha antitráfico.

Nas fontes selecionadas para análise, a primeira notícia no El País sobre desarticulação de organização de tráfico de mulheres aparece em 4 de julho de 2001, meses após a promulgação da Ley de Extrangería, que tipificou o tráfico de pessoas na Espanha, e começa assim:

A Brigada de Extrangería desarticulou uma organização dedicada ao tráfico de mulheres procedentes do Leste Europeu e da América Latina para prostituição, como informou a Direção Geral da Polícia. Foram presas 69 pessoas [...]. A operação começou no ano passado, durante o período de regularização de imigrantes, quando os investigadores detectaram irregularidades nas solicitações de várias estrangeiras. Começaram uma análise de sua documentação e das empresas que lhes apresentaram supostas ofertas de trabalho.

O tráfico de mulheres se constituiu na Espanha em foco de atenção justo no momento de grande preocupação com a imigração. Em 29 de agosto de 2001, El País anotou que a "crescente onda migratória para [a] Espanha fez florescer os negócios de organizações criminosas que se aproveitam da difícil situação dos estrangeiros irregulares" e que "este panorama levou à criação de Unidades contra Redes de Imigração e Falsidade Documental (Ucrif), dependentes da Direção-Geral de Polícia”. É muito enfática a preocupação com a imigração ilegal, que traz consigo redes de falsificação de documentos e movimentação financeira irregular. El País veiculou essa notícia em torno da criação de uma unidade contra "redes de imigração", e não sobre algum organismo encarregado de diminuir a exploração de imigrantes. Isso mostra sentidos dados ao tráfico que circulavam naquela sociedade. Em 12 de julho de 2002, a Folha de S. Paulo publicou que a "França quer expulsar prostitutas estrangeiras". Tratava-se de um projeto de lei propondo a expulsão de "estrangeiros dos dois sexos" que viviam da prostituição na França, apresentado pelo então ministro de segurança Nicolas Sarkozy. O jornal explicou que "a prostituição é um dos pontos mais delicados de plano de segurança [...]. Atualmente está relacionada na Europa aos fluxos migratórios para os países mais ricos. [...]. Muitos são 'importados' por redes mafiosas, que lhes exploram o trabalho sexual".

Tanto o jornal brasileiro quanto o espanhol publicizaram o debate sobre tráfico na última década. Contudo, até meados da década de 2000, a grande dis- 
cussão estava centrada nos lugares de destino, lugares que recebem migrantes, mas, após essa data, a discussão se globalizou..$^{15}$ Em 17 de dezembro de 2002, o jornal espanhol publicou elaborada reportagem, com cifras, gráfico e foto, articulando redes de imigração ilegal, prostituição, proxenetismo, tráfico de mulheres e exploração de menores. Assim se intitulou a reportagem: "Detidas 164 pessoas em uma operação contra imigração ilegal e proxenetismo em Madri”. Foi uma matéria publicada somente em meio eletrônico, e aparecia relacionada às seguintes notícias: "Defesa inclui imigração ilegal massiva entre as ameaças para a segurança nacional”, "A União Europeia gastará 934 milhões nos países de origem para frear imigração", "Detidos 77 imigrantes com documentação irregular na Andaluzia e Canárias", "Gráfico das correntes de imigração na União Européia”. E uma foto que mostrava um amontoado de pessoas com feições diferentes daquelas que identificamos como "europeias", chamada de "As portas da Europa". Os discursos que misturaram tráfico e imigração já se perdem entre si. Já não se sabe mais quem inventou essa conexão, nem bem ao certo a lógica que lhe dá impulso. O que podemos pensar, aqui, são as implicações práticas dessas formulações. Em 18 de dezembro de 2002, lemos notícia intitulada "Operação policial contra a imigração ilegal e proxenetismo". Em 17 de setembro de 2003, na notícia "Parlamento pede ao governo um plano contra o tráfico de mulheres", El País citou um informe que destacava que

o tráfico de seres humanos, em particular o de mulheres com fins de exploração sexual - muito lucrativo -, tem aumentado. A maioria das vítimas são mulheres da África subsaariana, da América Latina e do Leste Europeu, geralmente em extrema pobreza. Entre as 50 medidas propostas estão inspeções nas casas noturnas.

A maneira como se constituiu um saber sobre o tráfico permite apontar que pânicos anti-imigração, operações contra o tráfico e reforço no controle da prostituição fazem parte de um mesmo processo. Já não se sabe ao certo se a questão é imigração ou prostituição, se argumentos contra exploração sexual é que movem operações contra o tráfico, ou se são pânicos anti-imigração que favorecem o controle da prostituição, ou se é a prostituição que organiza redes migratórias, ou se são as redes migratórias que dão espaço à exploração. São discursos que compõem um ao outro.

\footnotetext{
${ }^{15}$ Apesar de a Espanha ser um dos principais pontos de destino do tráfico, também o Brasil exerce esse papel em menores proporções.
} 
É claro que, ao mesmo tempo em que esse discurso se articulou, apareceram vozes dissonantes. Se houve um reforço na condenação da prostituição, funcionando como efeito e instrumento da batalha contra o tráfico, houve também um discurso de resistência tentando se impor. Os discursos são estratégias. Em 14 de dezembro de 1999, lemos sobre o plano de legalização da prostituição proposto pela alcalde ${ }^{16}$ de Madri. Os grupos de oposição reagiram argumentando que o governo municipal deveria adotar medidas de erradicação de redes que traficam pessoas antes de cogitar medidas sobre uma possível regularização do "denominado ofício mais velho do mundo"; que era uma vergonha propor a regularização de uma atividade que consiste em exploração de mulheres em vez de denunciar o tráfico de pessoas; que a alcalde somente se preocupava com o dinheiro que move a prostituição; que viciadas em drogas e imigrantes se prostituíam por força da necessidade. O coletivo Hetaira, organização espanhola para a defesa dos direitos das mulheres prostitutas, se mostrava a favor de legalizar a prostituição por considerá-la um trabalho, mas exigia saber os objetivos da alcalde com uma possível regularização do setor. O governo municipal, segundo o jornal, apostava na regularização para desmantelar as máfias que exploram as mulheres. Podemos ler aí que, mais que um debate sobre máfias e imigrantes, o que estava em curso era uma disputa em torno da posição da alcalde: são citados nomes, partidos, apoiadores e opositores. E é bem nessas minúcias discursivas, aqui e ali, que o tráfico vai se delineando em embates, em disputas, nem sempre intencionalmente. Uma investigação histórica de como o tráfico de mulheres se constituiu em um problema exige uma análise de como os discursos foram colocados em funcionamento, de como foram disseminados e manifestados. El País deu considerável publicidade ao debate sobre a regulamentação da prostituição associado ao debate sobre tráfico justo no momento em que essa atividade esteve associada aos fluxos migratórios e foi alvo de atenção por parte daqueles que a condenavam. São movimentos coincidentes. Não quer dizer que um seja a causa do outro, mas que se sustentam, dão suporte e apoio um ao outro.

Em 11 de dezembro de 2000, assim foi publicado: "a chegada massiva de imigrantes deu um impulso ao mundo da prostituição na Espanha”. Nessa reportagem, El País estava tratando de um informe baseado em atendimentos médicos prestados a pessoas dedicadas à prostituição. Lemos também sobre dados

\footnotetext{
${ }^{16}$ Cargo semelhante ao de prefeita no Brasil, mas com competências judiciais.
} 
da Organização Internacional para as Migrações (OIM), comentados por um sociólogo empenhado em denunciar a exploração sexual de estrangeiras. Em 14 de fevereiro de 2001, quem fala são os bispos, que "pediram ao governo todos os esforços para regularizar os imigrantes" e se manifestaram contra o tráfico de mulheres na Espanha, "ainda que não se trate somente de um problema de imigrantes, mas de tráfico de brancas em geral”. Ora é a alcalde, ora são as organizações de trabalhadoras do sexo, por vezes são delegados e diplomatas, há também os sociólogos e os médicos, há os bispos e há até a historiadora arriscando um palpite. A questão não é procurar quem está dando a versão mais verdadeira, a questão é notar que todos esses discursos se encadeiam para formular um saber sobre o tráfico, pensar a maneira como se constituiu e se disseminou essa rede de saberes, fazendo aparecer exclusões e violências que foram colocadas em funcionamento no curso dessa prática discursiva.

Em 23 de abril de 2001, o jornal espanhol publicou notícia sobre tentativas dos bispos de "recuperar a imagem da Igreja": "os debates se centraram em problemas como o 'drama humano e moral do tráfico de mulheres', em assuntos de grande preocupação como a fragilidade da família do ponto de vista da hierarquia católica". No dia 27 de abril de 2001, a Igreja se manifestou novamente, dessa vez contra a "pílula do dia seguinte", e a notícia terminou com os seguintes dizeres:

Outro documento aprovado na Assembléia é relativo ao "drama humano e moral do tráfico de mulheres", tráfico que os bispos opinam ter estreita relação com os fluxos migratórios. O documento afirma que a vida cotidiana destas mulheres "é em muitos casos mais grave que a antiga escravidão" e denuncia que o cliente é a "peça-chave" da prostituição e "um colaborador fundamental para manter este degradante negócio".

Cada um com seu interesse específico, e que julga justo, juntos foram desenhando o tráfico. Em 28 de abril de 2001, lemos novamente sobre reivindicações dos bispos:

a pobreza e a banalização da sexualidade são algumas causas desse drama humano. Os bispos criticam também a tolerância legal dos Estados e asseguram que o endurecimento das leis de imigração agravam [sic] ainda mais esse problema porque "favorecem $[s i c]$ o desenvolvimento clandestino de máfias e traficantes" que manejam o negócio da prostituição.

Para os bispos, além da pobreza, foi a "banalização da sexualidade" uma causa de tráfico. Cada um foi produzindo um discurso associando questões espe- 
cíficas e de interesse particular. As fontes permitem apontar como se constituiu um saber sobre o tráfico na última década, como esse discurso/prática se constituiu associado à prostituição, à imigração, às máfias, ao crime, e como ele produz sujeitos, tem materialidade. O que se entende hoje como tráfico de mulheres foi constituído em embates, é efeito de relações de poder, não é simplesmente um reflexo, sendo, em si, uma prática, pois constitui coisas, constitui sujeitos. Para aqueles bispos, tráfico e prostituição estão colados, os dois são dramas morais. É o discurso que determina se certos sujeitos são aceitos, ou tolerados, ou rejeitados, ou excluídos.

Se os discursos são táticas, estão repletos de intenções e estratégias. Em 29 de outubro de 1998, a Folha de S. Paulo noticiava as queixas de uma mulher que dizia que sua filha estaria sendo mantida em cárcere privado, obrigada a se drogar e a se prostituir na Espanha. Os discursos que tornaram dizível o tráfico têm múltiplas miras. Ora são relatórios internacionais preocupados com a crescente onda migratória, ora é a polícia mostrando serviço, ora são as próprias vítimas pedindo ajuda. Se elas foram utilizadas pela polícia em operações contra o crime organizado, se são acusadas por atividades consideradas imorais ou por perturbar a ordem legal, também fazem funcionar o discurso jogando o jogo da vítima para obter algum benefício. Aqui e ali, esses discursos todos vão se encadeando e formulando um saber sobre o tráfico. Em 10 de setembro de 2001, quem falou de tráfico foi o então deputado Fernando Gabeira, ${ }^{17}$ em nome das "centenas de prostitutas e dezenas de travestis que me convidaram para seus congressos no Brasil e continuam me considerando um aliado confiável". Em 28 de outubro de 2001, foi a vez da cineasta Beatriz Flores Silva promover En La Puta Vida, filme de sua autoria: "[as mulheres] estão em maior situação de debilidade, assim como as crianças. Mas há também muitos jovens sem horizontes. Não quis fazer um filme feminista [...] mas a prostituta é ideal para mostrar essa contradição que existe nos modelos ditados pela sociedade". Em 18 de novembro de 2001, uma advogada citou o tráfico de mulheres entre formas de discriminação. Em 20 de junho de 2002, o secretário de Estado dos Direitos Humanos disse que "é necessário articular polícias”, e o representante policial disse que era necessário fisca-

\footnotetext{
${ }^{17}$ Fernando Gabeira é membro fundador do Partido Verde (PV) no Brasil, mas tem alternado sua participação política ora como membro do PT, ora do PV. Em 2008, candidatou-se ao cargo de prefeito do Rio de Janeiro pelo PV, em aliança com o PSDB e com o PPS. É popularmente conhecido por defender a profissionalização da prostituição e a descriminalização da maconha.
} 
lizar fronteiras e aeroportos. Foram citados resultados preliminares da Pestraf: "listou rodovias federais, hidrovias e aeroportos usados pelo tráfico". A Folha de S. Paulo explicou que a Pestraf estava articulada com outros levantamentos, todos baseados em um estudo-piloto da Organização dos Estados Americanos (OEA), e que foi elaborada a partir de "informações coletadas em fontes governamentais, ONGs, conselhos tutelares, registros da mídia, entrevistas com vítimas do tráfico, inquéritos na Polícia Federal e no Ministério Público em ações em varas da Justiça". Foi dito que a Pestraf também usou "registros de mídia", assim como esta pesquisa, ainda que com tratamento diferenciado. Então, a mídia relata notas policiais e relatórios sobre o tráfico, relatórios são produzidos com base em operações policiais e registros de mídia, as pesquisadoras escrevem sobre relatórios e discursos midiáticos. Estamos falando de discursos múltiplos que se encadeiam entre si, que evocam um ao outro. É nessa profusão que se produz um saber sobre o tráfico, que a lógica aparece, que enxergamos miras e objetivos diversos, mas não há mais como encontrar alguém que os tenha concebido ou formulado. E é a isso que Foucault se refere quando trata de invenção de saberes, de ficção discursiva: as formações históricas dizem o que podem dizer, veem o que podem ver, pois se produzem dentro de massas de enunciados. Não há como ver ou dizer o tráfico de pessoas fora das preocupações com respeito às migrações que marcaram a virada dos séculos XX e XXI.

As ideias sobre o tráfico de mulheres que circulam em nossa sociedade são elaboradas no interior de relações de poder. Essas relações de poder são, ao mesmo tempo, intencionais e não subjetivas, diz Foucault. ${ }^{18}$ São inteligíveis, não porque sejam simples efeito, como se houvesse uma causa que as explicasse, mas porque são atravessadas por um cálculo, são exercidas em função de miras e objetivos. Isso não quer dizer que resultem da escolha ou da decisão de um sujeito individual ou de um grupo. Não é sozinha que a editoria de um jornal, ou uma jurista, ou um grupo de funcionárias do governo decidem vitimizar ou criminalizar as pessoas envolvidas em redes de tráfico ou mesmo definem quem elas são. A racionalidade do poder é a das táticas muitas vezes bem explícitas no nível limitado em que se inscrevem, ensina o filósofo. Assim, a editoria tem em mira notícias que vendam o jornal, os governos têm em mira uma resposta a cobranças da sociedade e às relações internacionais, os operadores dos direitos humanos

\footnotetext{
${ }^{18}$ Michel Foucault, op. cit., 1988.
} 
pretendem diminuir as violências que acontecem no curso do tráfico, valendose, algumas vezes, de distorções discursivas conscientes para atingir seus objetivos. Essas articulações, encadeando-se entre si, invocando-se e propagando-se, encontrando em outra parte apoio e condição, esboçam finalmente dispositivos de conjunto. Assim, a manchete midiática, o depoimento daquela envolvida, a fala da juíza e da delegada, o discurso acadêmico, as conferências de profissionais do sexo, a opinião das pesquisadoras, todos esses discursos se encadeiam para constituir o fenômeno do tráfico. 